\title{
A Case of Habit Disorder: Sniffing Smell of Own Breath Using Fingers
}

\author{
${ }^{1}$ Tanujveer S Chandok, ${ }^{2}$ Sudhir Hebbar
}

\begin{abstract}
Habit disorders and impulse control disorders include conditions involving problems in self-control of emotions and behaviors. These are disorders which people generally neglect in day to day life as the symptoms are not severe, disabling or distressing. However, we present a case of 30 years old male with a habit disorder of sniffing smell of own breath using fingers, who responded well to fluoxetine.
\end{abstract}

Methodology: Patient who came to Psychiatry OPD, RajaRajeswari Medical College and Hospital was taken for case report.

ICD-10: Textbook was used to diagnose patient with Habit Disorder.

Keywords: Fluoxetine, Habit disorder, Sniffing

How to cite this article: Chandok TS, Hebbar S. A Case of Habit Disorder: Sniffing Smell of Own Breath Using Fingers. Int J Med Sci 2018;4(3):85-86.

Source of support: Nil

Conflict of interest: None

\section{INTRODUCTION}

Newspaper, The Guardian, 15th June 2016 reported that Joachim Low, head coach, and formal German football player was found to "... have shoved his hand into the front of his trouser and then smelled it afterward. He also did the same at the back..." The internet search using keywords 'compulsion to sniff body smell' reveals various social media discussions like Compulsive armpit sniffing, sniffing other people's feet and socks, etc... At this moment, we report a case of sniffing smell of own breath using fingers. The internet search did not reveal such case report earlier.

Habit disorders are classified in International Classification of Diseases and Related Health Problems (ICD-10) by World Health Organisation (WHO) under section F60-F69, disorders of adult personality and

\footnotetext{
${ }^{1}$ Postgraduate Student, ${ }^{2}$ Professor

1,2Department of Psychiatry, RajaRajeswari Medical College and Hospital, Bengaluru, India.
}

Corresponding Author: Tanujveer S Chandok, Postgraduate Student, Department of Psychiatry, RajaRajeswari Medical College and Hospital, Bengaluru, India, Mobile: +918427272121, e-mail: tanujveer41@gmail.com behaviour, F63, habit, and impulsive disorders which also includes pathological gambling, pathological fire-setting (Pyromania), pathological stealing (Kleptomania), trichotillomania, etc. ${ }^{1}$

Impulse control disorders/habit disorders are common psychiatric conditions in which affected individuals typically report significant impairment in social and occupational functioning. ${ }^{1}$ Impulsivity has been defined as a predisposition toward rapid, unplanned reactions to either internal or external stimuli without regard for negative consequences. ${ }^{2}$ They are characterized by repeated acts that have no clear rational motivation and that generally harm the patient's own interest and those of other people. The patient reports that the behavior is associated with impulses to act that cannot be controlled. ${ }^{3}$ There is the inability to resist an intense impulse or temptation. There is a mounting tension before the act which gets resolved by the same. A feeling of guilt may follow later.

Habit disorders are characterized by repetitive behaviors and impaired inhibition of these behaviors. The irresistible and uncontrollable behaviors characteristic of impulse control disorders suggests a possible similarity to the frequently excessive, unnecessary and unwanted rituals of obsessive-compulsive disorder (OCD). ${ }^{4}$

\section{CASE REPORT}

A 30-year-old male presented with complaints of getting repetitive thoughts of smelling his breath by using his fingers for 3 years. He used the palmar aspect of the index and middle finger to sniff the exhaled breath from mouth. The patient was referred from the ENT department to Psychiatry department after ruling out halitosis (bad breath). Daily on an average patient used to smell his own breath by using his fingers 15 to 20 times and he liked to do it. The patient also had allergic symptoms like body pain, redness in the eyes, running nose and skin rash (chronic urticaria) which developed about one year after the development of this habit. He was receiving treatment for urticaria from the Department of Dermatology. Patient attributed urticaria to this habit. Hence, he wanted treatment of sniffing habit in the hope of curing the urticaria. Patient felt bad as it was embarrassing for him to perform this habit in front of others. 
There was no past history of previously being shown to any doctor/psychiatrist for the same above complaints. Patient himself has tried methods like applying Vicks vaporub on the nose so that he should stop sniffing his breath again and again, but unfortunately, that did not work, and patient used to remove the applied vicks vaporub and start sniffing his own breath only, as he liked the same. Because of the same repetitive act patient started avoiding going out socially at times as he felt embarrassed doing the same thing and was unable to control it.

The patient started on Fluoxetine $20 \mathrm{mg}$ OD and was reviewed after 3 weeks. Patient reported 80\% improvement in the symptoms. From the average of sniffing his breath daily 1 to 20 times was reduced to 3 to 4 times a day. A phone call follows up after 2 months revealed that the patient is still using fluoxetine and maintaining well.

\section{DISCUSSION}

As the patient was sniffing out of an urge to smell instead of checking the quality of smell of breath, this case was diagnosed under section F63.8 Other habit and impulse disorders according to ICD-10. In the literature two cases of compulsive checking of the body, the odor is reported. ${ }^{5}$ However, this case does not appear to be an OCD, as the symptom was not ego dystonic. As the patient liked the smell, the act of sniffing is not aimed to reduce the discomfort as seen in tic disorder.

Most people with the problem of such habits of sniffing body parts may not come to medical attention as the symptoms are not disabling and distressing. This might explain the rarety of such case reports. Even in this case, the patient came to reduce his sniffing, as he thought it was causing allergic problems. In the absence of allergic symptoms, a patient might not have come to take treatment. A patient reported he had significant control over problems, but he wanted the complete cure as he thought this habit is causing allergic symptoms. It is interesting that the patient was using fingers (as highlighted in the title of the case report) instead of the palm or other means to sniff.

We tried fluoxetine in this patient as Selective Serotonin Reuptake Inhibitors (SSRIs) are used in other impulse control disorders like trichotillomania. This is the first report of successful use of fluoxetine in this type of habit disorder.

\section{CONCLUSION}

Thus, we report a rare case of habit disorder of 'sniffing own breath by using his fingers', and the patient showed a great response to fluoxetine $20 \mathrm{mg}$. As per our knowledge, no such case has been reported earlier.

\section{REFERENCES}

1. World Health Organization (2006) The ICD-10 classification of mental and behavioral disorders: Clinical descriptions and diagnostic guidelines. Geneva: World Health Organization.

2. Grant J.E., Potenza M.N. Compulsive Aspects of ImpulseControl Disorders. Psychiatric Clinics of North America. 2006; 29(2):539-551.

3. Grant JE, Odlaug BL, Kim SW. Impulse control disorders: Clinical characteristics and pharmacological management. Psychiatric Times. 2007;24(10):64-69.

4. Grant JE, Mancebo MC, Pinto A, Eisen JL, Rasmussen SA. Impulse control disorders in adults with obsessive compulsive disorder. Journal of Psychiatric Research. 2006;40(6): 494-501.

5. Maciej erdzi ski. Olfactory obsessions - individual cases or one of the symptoms of obsessive-compulsive disorder? An analysis of 2 clinical cases. Archives of Psychiatry and Psychotherapy. 2008;3:23-27. 